\title{
Myocardial recovery following pulsatile biventricular assist device support in infants: Report of 2 cases
}

Joseph Philip, MD, ${ }^{\mathrm{a}}$ Desiree Machado, MD, ${ }^{\mathrm{a}}$ Renata Shih, MD, ${ }^{\mathrm{a}}$ Archana Shenoy, MD, ${ }^{\mathrm{d}}$ Mohammed Ebraheem, MD, ${ }^{a}$ Kevin Sullivan, MD, ${ }^{\mathrm{a}, \mathrm{b}}$ Himesh Vyas, MD, ${ }^{\mathrm{a}}$ Dipankar Gupta, MD, and Mark Bleiweis, MD, ${ }^{\text {a,c }}$ Gainesville, Fla



Use of pulsatile ventricular assist devices (VAD) is a wellestablished strategy for supporting children with endstage heart failure (HF), as a bridge to heart transplant. In 2005, Stiller and colleagues ${ }^{1}$ described a cohort of 73 pediatric patients managed using Excor pumps (Berlin Heart Inc, Woodlands, Tex), of whom $12.5 \%$ were successfully weaned of support. Since then, there have been multiple reports of successful pulsatile VAD weans in children., Myocardial recovery has been usually reported within a window of 1 to 2 weeks, on extracorporeal support and longer on VAD support. ${ }^{3-5}$ Here, we describe 2 patients with HF requiring biventricular VAD (BiVAD) support, successfully weaned 2 and 6 months after VAD implantation.

\section{CASE 1}

A 6-month old girl $(7 \mathrm{~kg})$ was transferred for severe HF status postrepair of a late diagnosis of severe coarctation of the aorta $(\mathrm{CoA})$ with minimal residual gradient and requiring escalating inotropic support. Echocardiography demonstrated severely diminished biventricular systolic function and left ventricular end diastolic volume (LVEDVi) of $87.14 \mathrm{~mL}$ ( $z$ score, 8.02). The etiology for HF was likely multifactorial: late repair of severe $\mathrm{CoA}$, ischemic insult postbypass. Due to severe biventricular dysfunction, BiVAD support was initiated using Excor $10 \mathrm{~mL}$ pumps based on our institutional approach. LV biopsy at implant demonstrated interstitial fibrosis with no inflammation, patchy cardiomyocyte atrophy, and hypertrophy of LV

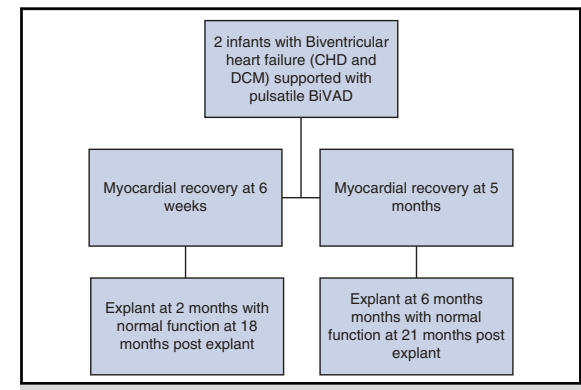

BiVAD, Pulsatile, Myocardial recovery, VAD wean

\begin{abstract}
CENTRAL MESSAGE
Delayed myocardial recovery post VAD implant has been well described in adults. In most cases, complete recovery has been reported in the first 4 to 6 weeks. Herein we report 2 cases of delayed myocardial recovery with successful VAD explant after 2 months and at 6 months in a pediatric population. One is a patient with CHD and the other with dilated cardiomyopathy, both on BiVAD support.
\end{abstract} See Commentaries on pages 93 and 95.

trabeculae (Figure 1, A). Surveillance echocardiograms were performed. Normalization of right ventricular function was noticed at 2.5 months. A gradual decrease in LVEDVi was noted over the next 2 months to $z$ score of +2 with improvement in LV function to normal at 4.5 months. Biventricular function was monitored over 4 weeks, with no evidence of deterioration. A weaning trial was performed (Table 1) and good hemodynamic parameters were measured by 

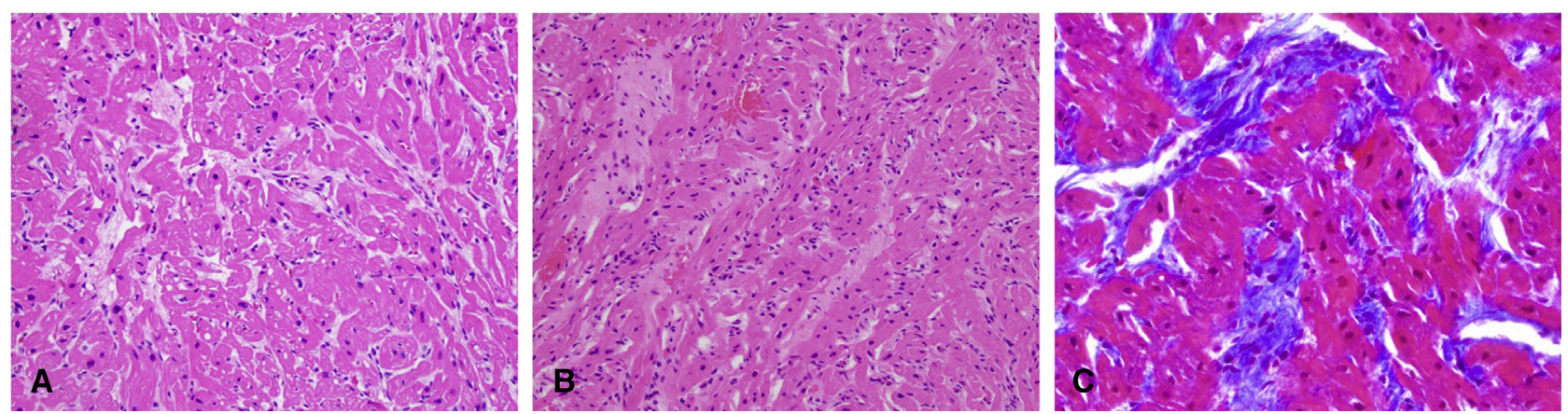

FIGURE 1. Left ventricular biopsy at implant. A, Case 1 : Left ventricular biopsy at implant- hematoxylin and eosin stained section (200× magnification) that demonstrates evenly spaced cardiomyocytes with mild interstitial expansion. Rare enlarged nuclei of hypertrophic cardiomyoctes are present. B, Case 2: Hematoxylin and eosin stained section (200× magnification) that demonstrates mild cardiomyocyte fiber size variation with focal interstitial fibrosis. C, Image $(400 \times$ ) magnification of a trichrome stained slide that confirms the interstitial fibrous expansion (blue-purple). The eosinophilic cardiomyocytes diameter ranges from 12 to 20 microns.

cardiac catheterization (Table 2). VAD was explanted with good clinical function (Table 3). Patient was changed to Status 7 (inactive) once evidence of recovery was seen. This patient is currently 21 months postexplant with normal function and no recurrent CoA (LVEDVi after explant was $23.44 \mathrm{~mL}$ ).

TABLE 1. University of Florida ventricular assist device (VAD) weaning protocol (heparin bolus 75 IU/kg, 15 minutes before VAD action)

\begin{tabular}{|c|c|c|}
\hline Day of wean & VAD action & Parameters monitored \\
\hline 1 & BiVAD rate decreased by $50 \%$ for $30 \mathrm{~min}$ & $\begin{array}{l}\text { Vital signs (heart rate, respiratory rate, blood pressure) every } \\
3 \text { min } \\
\text { Continuous NIRS } \\
\text { Mental status } \\
\mathrm{SvO}_{2} \text { measurement every } 10 \mathrm{~min} \\
\text { Echocardiogram every } 10 \mathrm{~min} \text { (left ventricular end diastolic } \\
\text { volume, ejection fraction, and qualitative assessment of } \\
\text { wall function) }\end{array}$ \\
\hline 2 & $\begin{array}{l}\text { BiVAD rate decreased by } 75 \% \text { or } 35 \text { (whichever was higher) } \\
\text { for } 30 \mathrm{~min} \text {; following this, BiVAD completely paused for } \\
3 \mathrm{~min} \\
\text { Important: Both pumps have to be manually pumped to fill } \\
\text { and eject every } 30 \mathrm{~s}\end{array}$ & $\begin{array}{l}\text { Same as Day } 1 \\
\mathrm{SvO}_{2} \text { measurement every } 10 \mathrm{~min} \text { and at the end of pause } \\
\text { Echocardiogram every } 10 \mathrm{~min} \text { and at the end of the pause } \\
\text { (size and function) }\end{array}$ \\
\hline 3 & $\begin{array}{l}\text { BiVAD rate decreased by } 75 \% \text { or } 35 \text { (whichever was higher) } \\
\text { for } 30 \mathrm{~min} \text {; following this, BiVAD completely paused for } \\
6 \mathrm{~min} \\
\text { Important: Both pumps have to be manually pumped to fill } \\
\text { and eject every } 30 \mathrm{~s}\end{array}$ & Same as Day 2 \\
\hline 4 & $\begin{array}{l}\text { BiVAD rate decreased by } 75 \% \text { or } 35 \text { (whichever was higher) } \\
\text { for } 30 \mathrm{~min} \text {; following this, BiVAD completely paused for } \\
10 \mathrm{~min} \\
\text { Important: Both pumps have to be manually pumped to fill } \\
\text { and eject every } 30 \mathrm{~s}\end{array}$ & Same as Day 2 \\
\hline $\begin{array}{l}\text { 5- Right heart } \\
\text { catheterization }\end{array}$ & $\begin{array}{l}\text { BiVAD rate decreased by } 75 \% \text { or } 35 \text { (whichever was higher) } \\
\text { for } 30 \mathrm{~min} \text {; following this, BiVAD completely paused for } \\
10 \mathrm{~min} \\
\text { Important: Both pumps have to be manually pumped to fill } \\
\text { and eject every } 30 \mathrm{~s}\end{array}$ & $\begin{array}{l}\text { Same as Day } 2 \text { with hemodynamic measurements in } \\
\text { catheterization include right atrial, right ventricular end } \\
\text { diastolic pressures, and pulmonary venous wedge } \\
\text { pressures in addition to estimating cardiac output }\end{array}$ \\
\hline
\end{tabular}

$V A D$, Ventricular assist device; $B i V A D$, biventricular assist device; $N I R S$, near-infrared spectroscopy; $\mathrm{SvO}_{2}$, mixed venous oxygen saturation. 
TABLE 2. Hemodynamic findings during the stages of wean from ventricular assist device (VAD)

\begin{tabular}{|c|c|c|c|c|c|c|c|}
\hline $\begin{array}{c}\text { Hemodynamics at } \\
\text { VAD wean }\end{array}$ & $\begin{array}{c}\text { RAP } \\
(\mathbf{m m ~ H g})\end{array}$ & $\begin{array}{c}\text { PAP } \\
(\mathbf{m m ~ H g})\end{array}$ & $\begin{array}{c}\text { PCWP } \\
(\mathrm{mm} \mathrm{Hg})\end{array}$ & $\mathrm{MvO}_{2}(\%)$ & SBP (mm Hg) & $\begin{array}{c}\text { PVR } \\
\text { (Wood units } / \mathbf{m}^{2} \text { ) }\end{array}$ & CI $\left(\mathrm{L} / \mathrm{min} / \mathrm{m}^{2}\right)$ \\
\hline \multicolumn{8}{|l|}{ Case 1} \\
\hline BiVAD rate $65 / 60$ & 11 & $27 / 18(21)$ & 12 & 60 & $121 / 62$ & 2.7 & 3.3 \\
\hline BiVAD rate $35 / 30$ & 12 & $28 / 13(21)$ & 14 & 59 & $105 / 57$ & 2.6 & 3.3 \\
\hline BiVAD paused $10 \mathrm{~min}$ & 13 & $37 / 17(25)$ & 14 & 58 & $120 / 66$ & 2.6 & 3.3 \\
\hline \multicolumn{8}{|l|}{ Case 2} \\
\hline BiVAD rate $75 / 70$ & 8 & $35 / 20(25)$ & 11 & 61 & $85 / 40$ & 3.6 & 3.8 \\
\hline BiVAD rate $35 / 30$ & 11 & $32 / 15(23)$ & 11 & 57 & $82 / 47$ & 3.2 & 3.7 \\
\hline BiVAD paused $10 \mathrm{~min}$ & 11 & $35 / 15(24)$ & 10 & 60 & $82 / 46$ & 3.5 & 3.9 \\
\hline
\end{tabular}

$V A D$, Ventricular assist device; $R A P$, right atrial pressure; $P A P$, pulmonary artery pressure; $P C W P$, pulmonary capillary wedge pressure; $M v O 2$, mixed venous saturation; $S B P$, systolic blood pressure; $P V R$, pulmonary vascular resistance; $C I$, cardiac index; BiVAD, biventricular assist device.

\section{CASE 2}

A 9-month-old girl $(8 \mathrm{~kg})$ was admitted with cardiogenic shock (biventricular dysfunction due to dilated cardiomyopathy), with initial LVEDVi of $87.2 \mathrm{~mL}$ ( $z$ score, 7.79). BiVAD support was initiated using Excor $10 \mathrm{~mL}$ pumps as a bridge to heart transplant. A biopsy from LV at VAD implantation showed cardiomyocyte size variation with patchy interstitial fibrosis without inflammation. (Figure 1, B). On surveillance, recovery in LV function with decrease in LVEDi was noticed at 4 weeks with recovery of right ventricle. LV function was normal at 6 weeks and was monitored for another 2 weeks. Weaning trial was performed at 8 weeks and was tolerated. The patient underwent successful a VAD explant. Follow-up echocardiogram showed LVEDVi of $24.51 \mathrm{~mL}$ ( $z$ score, 0.7 ) and currently the patient has normal biventricular function 18 months postexplant (Table 3).

\section{DISCUSSION}

Although recovery is well described in the adult population on VAD support, there is limited data in children using pulsatile VADs, with some of the case reports of recovery being on continuous flow devices. ${ }^{3-8}$ In 2016, Hezter and colleagues $^{3,9}$ described that $15 \%(n=18)$ of patients had recovery over a median time frame of 1 to 2 months. Ihnat and colleagues 5 reported a higher frequency of recovery than other cohorts- $61 \%$ (8 out of 13)-with the longest duration of support before wean being 21 days. Recovery was seen more frequently in myocarditis and idiopathic HF, with mean patient age $<2$ years. ${ }^{5}$

Current evidence suggests initial myocardial injury could arise from high levels of transforming growth factor beta and imbalance of the renin-angiotensin system, which promotes interstitial fibrosis and LV dilation with myocyte hypertrophy, respectively. ${ }^{10}$ Reverse modeling with VAD support has been seen in adults over longer time periods, leading to reduction in myocyte size and the area of fibrosis. ${ }^{11}$

Our imaging surveillance protocol includes echocardiogram twice a month for the first 3 months and monthly thereafter, monitoring LV dimensions, ejection fraction, and wall motion assessment. If wall motion recovery is noted, then imaging is performed weekly. Once function is identified as low normal qualitatively, ejection fraction $>45 \%$ to $55 \%$ with LVEDVi within $+2 z$ scores, a VAD wean trial is initiated after ensuring recovery is sustained over the next 2 to 4 weeks. Recurrence of HF postexplant has been described by Irving in 3 of 11 patients, requiring VAD reimplant and heart transplant. The etiology in all 3 was dilated cardiomyopathy. ${ }^{4}$ We suggest an active surveillance protocol for any signs of myocardial recovery in all pediatric patients with a VAD.

The authors thank Tilman Humpl, Christina Vander Pluym, Frederick Jay Fricker, and Dalia Lopez Colon for their expertise and guidance.

TABLE 3. Echocardiographic findings for patients 1 and 2 both at diagnosis and wean

\begin{tabular}{lcccccc}
\hline Patient & $\begin{array}{c}\text { LVEF } \\
\text { (at diagnosis) }\end{array}$ & $\begin{array}{c}\text { RV function } \\
\text { at diagnosis }\end{array}$ & $\begin{array}{c}\text { LVEDi }(\mathbf{c m}) \\
\text { at diagnosis }\end{array}$ & $\begin{array}{c}\text { LVEF at } \\
\text { VAD wean }\end{array}$ & $\begin{array}{c}\text { RV function } \\
\text { at VAD wean }\end{array}$ & $\begin{array}{c}\text { LVEDi (cm) } \\
\text { at VAD wean }\end{array}$ \\
\hline 1 & $8 \%-10 \%$ & Severely depressed & $8.4(z$ score,+8$)$ & $55 \%-60 \%$ & Normal & $3(z$ score, +1.5$)$ \\
2 & $5 \%-7 \%$ & Mildly depressed & $4.4(z$ score,+9$)$ & $60 \%-65 \%$ & Normal & $2.34(z$ score,-1$)$ \\
\hline
\end{tabular}

$L V$, Left ventricle; $E F$, ejection fraction; $R V$, right ventricle; $L V E D i$, left ventricular end diastolic dimension; $V A D$, ventricular assist device. 


\section{References}

1. Stiller B, Lemmer J, Schubert S, Ewert P, Schulze-Neick I, Hübler M, et al. Management of pediatric patients after implantation of the Berlin Heart EXCOR ventricular assist device. ASAIO J. 2006;52:497-500.

2. Hetzer R, Potapov EV, Stiller B, Weng Y, Hübler M, Lemmer J, et al Improvement in survival after mechanical circulatory support with pneumatic pulsatile ventricular assist devices in pediatric patients. Ann Thorac Surg. 2006;82:917-24.

3. Zimmerman H, Covington D, Smith R, Copeland J. Mechanical support and medical therapy reverse heart failure in infants and children. Artif Organs. 2010;34:885-90.

4. Irving CA, Crossland DS, Haynes S, Griselli M, Hasan A, Kirk R. Evolving experience with explantation from Berlin Heart EXCOR ventricular assist device support in children. J Heart Lung Transplant. 2014;33:211-3.

5. Thnat CL, Zimmerman H, Copeland JG, Meaney FJ, Sobonya RE, Larsen BT, et al. Left ventricular assist device support as a bridge to recovery in young children. Congenit Heart Dis. 2011;6:234-40.
6. Dandel M, Weng Y, Siniawski H, Potapov E, Krabatsch T, Lehmkuhl HB, et al. Pre-explant stability of unloading-promoted cardiac improvement predicts outcome after weaning from ventricular assist devices. Circulation. 2012; 126(11 Suppl 1):S9-19.

7. Cavigelli-Brunner A, Schweiger M, Knirsch W, Stiasny B, Klingel K, Kretschmar O, et al. VAD as bridge to recovery in anthracycline-induced cardiomyopathy and HHV6 myocarditis. Pediatrics. 2014;134:e894-9.

8. Lowry AW, Adachi I, Gregoric ID, Jeewa A, Morales DL. The potential to avoid heart transplantation in children: outpatient bridge to recovery with an intracorporeal continuous-flow left ventricular assist device in a 14-year-old. Congenit Heart Dis. 2012; 7:E91-6.

9. Hetzer R, Kaufmann F, Delmo Walter EM. Paediatric mechanical circulatory support with Berlin Heart EXCOR: development and outcome of a 23-year experience. Eur J Cardiothorac Surg. 2016;50:203-10.

10. Opie LH, Commerford PJ, Gersh BJ, Pfeffer MA. Controversies in ventricular remodeling. Lancet. 2006;367:356-67.

11. Yamada Y, Saito S, Nishinaka T, Yamazaki K. Myocardial size and fibrosis changes during left ventricular assist device support. ASAIO J. 2012;58:402-6. 